\title{
UM BREVE LEVANTAMENTO SOBRE O CONSUMO NA GRÉCIA- 1960-2010 ${ }^{1}$
}

\section{A short review of consumption in Greece: 1960-2010}

\section{Una breve encuesta sobre consumo en Grecia: 1960-2010}

\author{
Emmanouel Heretakis ${ }^{2}$
}

\section{Resumo}

O avanço neoliberal desregulamentado das lógicas produtivas dos sistemas de comunicação de massa foi uma realidade extrema para um grande número de países na última parte (se não antes) da década de 1980. Ao mesmo tempo, o fato de que as pessoas estavam sendo gradualmente persuadidas (com a ajuda da crescente presença publicitária) a incrementar seu consumo de mercadorias foi uma parte essencial da estrutura geral da economia, sublinhando o consumismo como uma consequência necessária na composição das sociedades modernas. Quase todo mundo estava feliz. Foi uma situação onde se passou da pobreza à riqueza. No final da década passada, a situação já era completamente diferente. A situação financeira e do universo da mídia é completamente diferente daquela vivenciada na década de 1980. Poder-se-ia dizer que vivenciamos uma situação de passar da riqueza à pobreza para um número significativo de países, incluindo Itália, Irlanda, Espanha e Portugal. A Grécia foi o país onde as dificuldades financeiras foram mais evidentes; potencialmente outros países seguiram esse caminho. As cruciais mudanças que têm acontecido fazem sentir a urgência de repensar e redesenhar as práticas e conceitos que se consideravam estáveis por várias décadas. Neste artigo apresentaremos um quadro histórico de 1960 a 2010 das relações mídia e consumo na Grécia, tendo como principal objetivo discutir: os sentidos do consumo na Grécia;

\footnotetext{
1Tradução do inglês para o português realizada por Nicolás Llano Linares - Doutorando do PPGCOM/USP.

${ }^{2}$ Professor Associado da Faculdade de Comunicação e Mass Media, da Universidade de Atenas, Grécia. Email: eheretak@media.uoa.gr. Artigo realizado na condição de professor visitante financiado pelo CNPq, junto ao Departamento de Relações Públicas, Propaganda e Turismo e do Programa de Pós-Graduação em Ciências da Comunicação da Escola de Comunicações e Artes da Universidade de São Paulo, Brasil.
} 
ascenção e queda dos investimentos publicitários no país, buscando oferecer um panorama que leve à reflexão sobre o contexto atual vivido na realidade grega.

Palavras-chave: mercados mundiais, taxa de crescimento, mídia, publicidade, desregulamentação, cultura de consumo, estilo de vida, cultura visual.

\begin{abstract}
Mass media deregulation was a stark reality for a good number of countries, towards the last part (if not earlier) of the 80's. At the same time, the fact that people were gradually persuaded ( with the help of continuously growing advertising ) to increase their consumption of commodities was an essential part of a general frame of the economy, heralding the rise of consumerism as a necessary sequel of the life blood of modern societies. Advertising expenditure was booming; new media outlets -particularly electronic -were founded. Almost everybody was happy. It was a "rags to riches" situation. Towards the end of the 2000 decade, the situation is almost different. The financial and the overall media situation in most countries is entirely different from the 80 's. One could say that it was a "from riches to rags" situation for quite a number of countries, including Italy, Ireland, Spain and Portugal. Greece was the first country where its financial difficulties were more than evident; potentially, other countries will follow suit. The pivotal changes that have taken place, already lead to the necessity of totally rethinking and redesigning practices and concepts that were thought as being stable for over a number of decades. In this paper we present a historical 1960-2010 media relations and consumption in Greece, with the primary objective to discuss: the meanings of consumption in Greece; rise and fall of advertising investments in the country, seeking to provide an overview that leads to reflection on the current context lived in Greek reality.
\end{abstract}

Keywords: supermarkets; rate of growth; media; advertisements; deregulation; consumer culture; lifestyle; image culture;

\title{
Resumen
}

El avance desregulado lógicas neoliberales de los sistemas productivos de la comunicación de masas ha sido una realidad para el momento un gran número de países en la última parte (si no antes) el decenio de 1980. Al mismo tiempo, el hecho de que la 
gente se estaba convencida gradualmente (con la ayuda de aumento de la presencia de publicidad) para aumentar su consumo de bienes era una parte esencial de la estructura general de la economía, haciendo hincapié en el consumismo como una consecuencia necesaria de la composición de las sociedades moderna. Casi todo el mundo estaba contento. Era una situación en la que se pasó de la pobreza a la riqueza. Al final de la última década, la situación era completamente diferente. La situación financiera y el universo de los medios es completamente diferente a la que se vivió en la década de 1980. Se podría decir que vivimos una situación de pasar la riqueza a la pobreza para un número importante de países, entre ellos Italia, Irlanda, España y Portugal. Grecia fue el país en el que las dificultades económicas eran evidentes, potencialmente, otros países siguieron este camino. Los cambios fundamentales que han ocurrido sintieron la urgencia de repensar y rediseñar las prácticas y conceptos que se consideran estables durante varias décadas. En este trabajo se presenta un histórico 1960-2010 de las relaciones del consumo y los medios de comunicación en Grecia, con el objetivo principal de discutir: los significados del consumo en Grecia e ascenso y caída de la inversión publicitaria en el país, donde se busca ofrecer una visión general que lleva a la reflexión sobre el contexto actual que la gente vive en la realidad griega.

Palabras-clave: mercados mundiales, tasa de crecimiento, la publicidad los medios de comunicación, la desregulación, la cultura de consumo, estilo de vida, la cultura visual.

\section{INTRODUÇÃO}

O avanço neoliberal desregulamentado das lógicas produtivas dos sistemas de comunicação de massa foi uma realidade extrema para um grande número de países na última parte (se não antes) da década de 1980. Ao mesmo tempo, o fato de que as pessoas estavam sendo gradualmente persuadidas (com a ajuda da crescente presença publicitária) a incrementar seu consumo de mercadorias foi uma parte essencial da estrutura geral da economia, sublinhando o consumismo como uma consequência necessária na composição das sociedades modernas. Quase todo mundo estava feliz. Foi uma situação onde se 
passou da pobreza à riqueza ${ }^{3}$. No final da década passada, a situação já era completamente diferente. A situação financeira e do universo da mídia é completamente diferente daquela vivenciada na década de 1980. Poder-se-ia dizer que vivenciamos uma situação de passar da riqueza à pobreza para um número significativo de países, incluindo Itália, Irlanda, Espanha e Portugal. A Grécia foi o país onde as dificuldades financeiras foram mais evidentes; potencialmente outros países seguiram esse caminho. As cruciais mudanças que têm acontecido fazem sentir a urgência de repensar e redesenhar as práticas e conceitos que se consideravam estáveis por várias décadas. Neste artigo apresentaremos um quadro histórico de 1960 a 2010 das relações mídia e consumo na Grécia, tendo como principal objetivo discutir: os sentidos do consumo na Grécia; a ascenção e queda dos investimentos publicitários no país, buscando oferecer um panorama que leve à reflexão sobre o contexto atual vivido na realidade grega.

\section{A RESPEITO DO CONSUMO}

Durante os anos de 1960 as mercearias foram considerados os referentes centrais das compras cotidianas na estrutura doméstica. Estes espaços criaram uma relação pessoal com os clientes; as pessoas compravam bens não só com base na sua aparência, mas também baseados na relação pessoal que se tinha com os donos/funcionários. Outro fator a considerarmos nessa relação era a honestidade que o dono/funcionário da loja demonstrava, pois ao não fazer batota quando se pesavam os alimentos. Assim, o cliente estabelecia um vínculo mais estreito com esses espaços e com as pessoas que trabalhavam neles.

O dono do bar oferecia vinho diretamente dos barris que ele abria todos os anos durante a festa de São Dimitrios (realizada em 26/10), e um grande número deles colocava pequenas mesas na calçada para convidar a seus clientes a um copo do seu vinho. O conceito de supermercado era inteiramente desconhecido na Grécia durante os anos sessenta ${ }^{4}$.

\footnotetext{
${ }^{3}$ Nota do tradutor no texto original aparece a expressão "from rags to riches".

${ }^{4}$ Para aprofundar de forma quantitativa sobres os detalhes relacionados ao consumo na Grécia de 1960 a 2000. Ver Heretakis(2010, p. 479-590).
} 
A transição de mercearias para os supermercados começou durante os últimos anos da década de 1960 e se concluiu nos últimos anos da década de 1980. O que desapareceu, e nunca foi restaurado, foi a relação pessoal entre os clientes e o proprietário da mercearia, o que consistia no tempo disponível para uma pequena conversa. As compras estavam baseadas nas listas de compras, escritas ou na mente do cliente, uma vez que na maioria dos casos, estes já sabiam o que queriam comprar. Houve algumas vezes, principalmente para bens em pequenas quantidades, por exemplo, açúcar, sal, limões, que um número de famílias pegava emprestado em pequenas quantidades dos vizinhos (tendo em conta o direito de retribuir, quando a necessidade surgisse).

A publicidade ainda não tinha obtido a influência que adquiriu depois da década de 1970, devido ao número limitado de anúncios e ao fato de que esta novidade não tinha construído pontes comuns e espaços de encontro com a cultura da maioria de pessoas.

Durante os anos de 1960, Grécia exibiu uma alta taxa de crescimento, o desemprego foi de cerca de 5\% da população ativa. No decorrer dos anos de 1960 novos padrões de consumo começaram aparecer, e junto com eles anúncios de detergentes importados, sabões feitos em casa e outros bens de higiene pessoal, enquanto a imprensa começava usar a publicidade como uma espécie de moeda de troca entre eles (quer dizer, um jornal se anunciava numa revista e a revista fazia o mesmo reciprocamente no jornal).

De forma indireta, o fato de que um número de pessoas compraram produtos nesses novos espaços (supermercados) já era uma indicação da nova prosperidade financeira relacionada com aqueles que não praticavam essa novidade. De fato, essa justaposição entre essas duas formas diferentes de distribuição manteve sua existência por um bom tempo, mesmo após a dominação dos supermercados na Grécia. Por seu tamanho, os supermercados poderiam encomendar e comprar grandes quantidades de produtos a seus preços eram significativamente mais baixos do que nas mercearias, portanto, conseguiam oferecer aos seus clientes preços muito mais competitivos para os mesmos produtos, enquanto as mercearias não podiam reduzir de forma tão radical seus preços.

A mídia impressa, principalmente os jornais, era o meio essencial tanto de informação, quanto de vinculação de publicidade até o final da década de 1970. Apesar do crescimento na circulação até a Ditadura Militar Pós-Guerra, o período de 1967-1974 
apresentou uma tendência decrescente, restaurada após a queda da Ditadura em 1974. Desde 1974 até a primeira década dos anos de 1980, os jornais retomaram a tendência de crescimento, continuada quase ininterruptamente até os anos finais da mesma década. As revistas apresentaram um aumento de vendas durante o período 1960-1980, mesmo com um número reduzido de títulos disponíveis; revistas de consumo em sua maioria que incluía um número considerável de anúncios publicitários entre suas páginas.

O rádio tinha virado uma fonte importante de informação e entretenimento, importância palpável desde o início dos anos 60 com a transmissão sistemática diária das novelas radiofônicas. O alcance do rádio foi aumentado com a aparição do transistor, facilitando dessa forma a portabilidade da informação. Os radioamadores começaram experimentar com o meio e, como conseqüência desse incremento de uso, o rádio construiu um público considerável até o final da década de 1970.

A televisão apareceu no cenário da mídia grega na segunda parte dos anos 1960 e, posteriormente, ajudou criar um interesse para o novo formato narrativo: o seriado de televisão, que era na verdade, um descendente da novela radiofônica. O contínuo aumento do número de aparelhos de tevê durante o período de 1960-2000 (aumento que continuo mesmo depois desse período, como também aconteceu como o rádio), se estabeleceu e expandiu a partir da constituição de uma nova audiência (televisão e rádio), com programas de entretenimento, tornando-se os pratos principais do cardápio oferecido. A propaganda da Ditadura Militar foi consideravelmente ajudada pela gradual expansão de aparelhos de rádio e TV.

Na década de 1970 evidenciamos a expansão da imprensa, juntamente com a televisão e a publicidade; sendo estes dos últimos elementos pilares essenciais do consumo e da evolução do consumismo. Novos investimentos de capital estrangeiro provocaram protestos dos proprietários dos capitalistas locais e, em pouco tempo, o capital estrangeiro atingiu uma poderosa influencia política do país, tendo de enfrentar os interesses empresariais gregos, que estavam evidentemente aliados ao pessoal da política doméstica (interna).

Desde os anos 1970 um número de pessoas seguiu uma estratégia comercial de dois gumes, embora os supermercados já tivessem se estabelecido, já que possuíam a maioria do volume de compras, no entanto, as pessoas continuaram comprando produtos 
das mercearias em decadência (financeira) assim como também iam às feiras-livres (principalmente para compra de produtos frescos).

De 1973 até 1981, a taxa de crescimento apresentou várias flutuações, acompanhada por altos níveis de inflação. Em contraposição, o desemprego manteve-se baixo até o final dos anos de 1980, e a renda per capita apresentou aumentos nada insignificantes. Durante a década supracitada, a taxa de crescimento tinha diminuído (tornando-se negativa após vários anos), enquanto existia um alto nível de inflação e desemprego desde 1981. A renda per capita, depois de uma série de flutuações bruscas durante os primeiros anos da década de 1980, aumentou (pelo menos em preços atuais) desde meados da década de 1980.

Na mesma década, a Grécia tornou-se membro da Comunidade Européia. Fato importante que ajudou na consolidação do marketing e teve uma influência significativa na publicidade. A entrada de agências de publicidade internacionais (a maioria de origem americana e britânica) ao mercado grego se intensificou devido aos acordos de cooperação pautados com os respectivos órgãos gregos. Os padrões de consumo e os hábitos da maioria da população começaram-se modelar de forma semelhante aos dos grandes países europeus, enquanto instituições como a família foram afetadas de forma gradual.

Os resultados da expansão do consumo favoreceu o aumento do crédito ao consumidor, principalmente durante a segunda metade da década de 1980, e continuou constante até o início de 2010.

A importância da publicidade se intensificou na Grécia e em outros países europeus, usando novos métodos de persuasão junto com as práticas tradicionais; essa expansão da atividade publicitária teve um importante papel no desmantelamento gradual do tradicional (o já existente), das mudanças nas convenções sociais e, de forma significativa, na despolitização dos chamados consumidores, assim como na glorificação de marcas de produtos internacionais, e na diminuição das vendas das marcas nacionais.

A desregulação da mídia eletrônica durante os anos de 1980, trouxe para a frente as estações privadas de rádio e, um pouco depois, as estações privadas de televisão. A desregulação foi fundada em terrenos legais instáveis, e a utilidade das licenças a curto prazo concedidas por parte de governos sucessivos incrementaram o clima de incerteza, 
o qual favoreceu a classe política do país. A mídia se mercantilizou completamente, como um incremento importante na a inversão publicitária, a qual durou até a metade da primeira década deste século. Ao mesmo tempo, novos meios de comunicação começaram aparecer no mercado, como os celulares, carregando consigo uma alta taxa de aceitação entre o grande público, especialmente entre os mais jovens.

A década de 1980 apresentou um tipo de consumismo ideológico; a mercearia aparecia como uma lembrança distante; os clientes dos supermercados trocaram a lista de compras pelo impulso de encher os carrinhos; esses mesmos clientes se fecharam em si mesmo, e claro, já não pediam emprestado para os vizinhos como acontecia nos anos de 1960. O individualismo virou uma característica dominante, de forma paralela existia a certeza de que para os problemas sociais (os quais eram sentidos de forma marcada) não existia uma solução coletiva, só esforços individuais - um resultado direto da dominância ideológica do neoliberalismo _,dentro de um universo de signos e conceitos. Universo no qual a publicidade tinha uma influencia importante sobre as pessoas. A publicidade tinhase estabelecido no próprio coração da cultura de consumo, destacando a superficialidade como sua característica principal.

O paradoxo foi que essa cultura do consumo (ou consumismo) emergiu como um fiador do progresso financeiro e das liberdades individuais: uma afirmação que tinha como objetivo fomentar com determinação uma obsessão (e não um ponto de vista ideológico) com um futuro que estava em rápido declínio até meados da década de 2000. Os preços dos produtos e serviços aumentaram rapidamente desde 1970 e daí em diante issoo foi uma prova evidente de que estas afirmações em prol do mercado livre e suas conseqüências positivas de desenfreada concorrência eram pouco fundamentadas, em qualquer sentido e completamente erradas.

Durante a década de 1990, as taxas de crescimento estavam em declínio até chegar às vezes a valores negativos, com uma tendência crescente durante os últimos anos da década, enquanto que os altos níveis de inflação do início dos anos de1990 estavam em declínio. Por outra parte, as taxas de desemprego apresentavam um comportamento inverso ao da inflação: esta tendia a aumentar quando os níveis de desemprego estavam diminuindo, enquanto o ingresso per capita aumentava com 
algumas variações ocasionais. Descobertas recentes ${ }^{5}$ indicam que a vida cotidiana da maioria dos habitantes da Grécia está agravada pela insegurança, angústia e descontentamento, conceitos que descrevem o clima geral da sociedade, e mostram de forma explicita tanto a queda nos padrões de vida, quanto a transição final da sociedade do desejo à da necessidade.

A festa interminável do consumo e a dominância do consumismo duraram, aproximadamente, até a metade dos anos 2000. A súbita demolição desse estilo de vida caracterizado com o consumismo e sua edificação individualista, expressada e propagada especialmente por alguns programas de televisão e várias revistas, mal conseguiram enfrentar as medidas financeiras de austeridade que inicialmente foram impostas sobre a Grécia e depois aplicadas a outros países Europeus, com conseqüências dramáticas para as diferentes sociedades.

A imprensa, tanto os jornais como as revistas, sofreram diminuições drásticas na circulação dos seus produtos (valores equivalente às perdas de vendas), o que foi seguido por uma queda significante em seu retorno da inversão publicitário ${ }^{6}$. Graves diminuições salariais na Grécia foram impostas pelo comitê trilateral do FMI, do BCE e da $\mathrm{UE}^{7}$, (a "troika"), para o final da década de 2000, com repercussão direta na contínua diminuição do consumo e no aumento da paralisação das pequenas empresas no território nacional. Para o final da década de 2000, o desemprego dos jovens atingiu a marca de 50\%, enquanto o desemprego da população geral foi de pelo menos de $20 \%$ (segundo dados oficiais) da população ativa.

\section{A ASCENSÃO E A QUEDA DO GASTO PUBLICIT ÁRIO}

Uma volta ao passado: na Grécia, o total dos gastos publicitários em 2010 ficou em torno do valor correspondente a $€ 1.887 .500 .000$ (milhões de Euros). Tal valor foi similar ao de 2003, calculado em $€ 1.806 .400 .000$ (milhões de Euros). O gasto publicitário em jornais em $2010 € 434.100 .000$ (milhões de Euros) foi parecido com o registrado durante 2006, no valor de $€ 452.4000 .000$ (milhões de Euros), enquanto o

\footnotetext{
${ }^{5}$ Ver a pesquisa Focus-Bari “Contemporary Trends, Novembro 2008. (Em inglês).

${ }^{6}$ Tema discutido e aprofundado no próximo item deste artigo.

${ }^{7} \mathrm{O}$ International Monetary Fund (IMF), o European Common Bank (ECB) e a European Union (EU).
} 
Um breve levantamento sobre o consumo na Grécia: 1960-2010

de Emmanovel Heretakis

gasto publicitário em revistas durante 2010 foi de 746.000 .000 (milhões de Euros) se aproximando ao notado em 2004 no valor de $€$ 803.500.000 (milhões de Euros). Por outra parte, o gasto publicitário no rádio durante 2010 foi de $€ 124.200 .000$ (milhões de Euros) e se assemelhou àquele anotado em 2006 no valor de $€ 119.400 .000$ (milhões de Euros), enquanto o gasto em televisão durante 2010 foi de 583.200 .000 (milhões de Euros), semelhante aos dados de 1999, no valor de € 613.100.00 (milhões de Euros).

Tabela 1- Gasto publicitário na Grécia (em milhões de Euros)

\begin{tabular}{|c|c|c|c|c|c|}
\hline Ano & Jornais & Revistas & Rádio & Televisão & Total \\
\hline 1991 & $45.9 \mathrm{~m}$ & $73.7 \mathrm{~m}$ & $17.2 \mathrm{~m}$ & $162.8 \mathrm{~m}$ & $299.6 \mathrm{~m}$ \\
\hline 92 & 59.3 & 101.5 & 27.0 & 300.0 & 487.8 \\
\hline 93 & 70.4 & 106.0 & 44.3 & 389.2 & 609.9 \\
\hline 94 & 94.9 & 134.8 & 52.9 & 558.1 & 840.7 \\
\hline 95 & 123.2 & 168.4 & 69.5 & 836.5 & 1197.6 \\
\hline 96 & 125.1 & 190.6 & 65.8 & 446.0 & 827.5 \\
\hline 97 & 159.6 & 273.8 & 65.8 & 466.2 & 965.4 \\
\hline 98 & 197.1 & 326.7 & 55.8 & 511.8 & 1091.4 \\
\hline 99 & 256.1 & 380.8 & 69.0 & 613.1 & 1319.0 \\
\hline 2000 & 302.5 & 470.4 & 70.5 & 665.1 & 1508.5 \\
\hline 01 & 255.3 & 532.2 & 70.8 & 661.0 & 1519.3 \\
\hline 02 & 253.5 & 604.0 & 87.7 & 712.6 & 1657.8 \\
\hline 03 & 302.5 & 684.7 & 98.5 & 720.7 & 1806.4 \\
\hline 04 & 352.9 & 803.5 & 115.6 & 771.1 & 2043.1 \\
\hline 05 & 407.4 & 886.3 & 113.9 & 784.7 & 2192.3 \\
\hline 06 & 452.4 & 978.3 & 119.4 & 793.6 & 2343.7 \\
\hline 07 & $499.7 \mathrm{M}$ & 1047.9 & 165.6 & $941.5 \mathrm{M}$ & 2654.7 \\
\hline 08 & 478.6 & $1113.3 \mathbf{M}$ & $214.9 \mathrm{M}$ & 862.0 & $2668.8 \mathrm{M}$ \\
\hline 09 & 441.7 & 889.8 & 166.2 & 714.8 & 2212.5 \\
\hline 2010 & 434.1 & 746.0 & 124.2 & 583.2 & 1887.5 \\
\hline
\end{tabular}

(*) Honorários de remuneração das agências de publicidade e seus correspondentes VAT não estão incluídos. M:Máximo, m: Mínimo. Fonte: Media Services of Greece.

A imagem que estes dados nos permite construir em termos do gasto publicitário é que há uma volta ao passado, embora a história tivesse começado com auspícios favoráveis. No caso da Grécia, o anunciado desregramento das mídias eletrônicas provou ser uma oportunidade de investimento para outros setores, não para aqueles normalmente 
relacionados com a indústria editorial e da mídia eletrônica, tal como os setores de transporte e envios, construção e finanças.

O tardio advento da televisão privada na Grécia em 1989-90 engatilhou uma atividade frenética de expansão dos grupos de negócios locais num mercado novo e virtualmente desregulado. A maior parte do capital de investimento que tinha como objetivo esse novo Eldorado não se originou da imprensa existente ou das empresas editoriais como de outros setores como transportes e envios, construção e finanças. A concentração de poder econômico resultante, corporificada por um número reduzido de famílias, rapidamente se traduziu em poder político, que pouco tinha sido afetado pelas sucessivas revisões da legislação grega da mídia durante 20 anos (YANNOPOULOS 2011, p. XX).

Do mesmo modo,

a situação grega é bastante similar: industriais com interesses comerciais nos setores de transporte e envios, viagens, construção, telecomunicações e empresas de petróleo dominam a posse dos meios de comunicação, e uma longa tradição de uso da mídia como um meio de pressão aos políticos que ainda continua” (HALIN, MANCINI s.d: 114$115)$.

O resultado, por exemplo, foi a concentração do poder econômico, distribuído entre um numero muito reduzido de famílias, o qual "rapidamente se traduz em poder político, o qual pouco tem sido afetado pelas sucessivas revisões da legislação da mídia grega nos últimos 20 anos" (YANNOPOULOS 2011: XX).

O simples fato de que esse poder político não foi afetado pelas sucessivas revisões da legislação da mídia na Grécia durante os últimos 20 anos é o ponto crucial do assunto. Segundo um comentarista da situação:

Não é exagerado afirmar que no caso da televisão comercial o prospecto de poder (político) está em jogo pelo menos pelos próximos 50 anos [...] As possibilidades existentes são duas: que o marco regulatório proteja a concorrência do recém-formado mercado televisivo, dos indivíduos-empresários privados entre eles, e que a televisão pública (estatal) seja forçada a se adaptar aos novos fatos, ou que a chamada liberação da televisão vire um assunto fechado entre um pequeno círculo de financistas e que tenham todas as razões para juntar forças e monopolizar o mercado. E de forma paralela formem um bloco de poder de empreendedores, com o poder de ditar os termos da vida política do país (TILETHEATI 1989: 40).

Esta é a forma de jogar a alta política no meio dos meios de comunicação de massa, e também um modo de entrar na "terra prometida" do consumo sem limites a partir da publicidade ininterrupta e, é exatamente isso, o que reflete a realidade grega. Realidade esta em que o país não se encontra sozinho, pois se consideramos, por 
exemplo, o paradigma italiano ${ }^{8}$, assim como o caso recente que aconteceu com "News of the World", na "News International" inglesa, propriedade de Rupert Murdoch.

A televisão e sua adoção universal é o verdadeiro predecessor da chamada "cultura de tela", ou seja, da proliferação de imagens e seus canais de distribuição ubíquos que permitem uma personalização da tela da televisão. Essa foi a primeira etapa na busca de expandir as possibilidades de assistir televisão. Considerando-se também o resultado da constituição de numerosas audiências, combinada com a sempre expansível aplicação de métodos quantitativos para suas avaliações na busca da quantificação dessas audiências.

No caso grego, a possibilidade de uma erosão causada por essa "cultura da imagem" do consumo mundializado foi altamente perigosa para os interesses de longo prazo do capital estatal e privado do país, já que acabou por resultar na avaliação e adoção de novas alternativas tomadas por parte da grande maioria dos empresários de mídia, vislumbrando outra lógica de modelo de comunicação para o país, dependente da produção midiática internacional. Por exemplo, as audiências massivas e, particularmente, no caso onde a NEA (Não Existe Alternativa), pelo domínio hegemônico do dogma neoliberal do "ambiente" midiático com produção quase toda externa, os espaço de disputa e de produção midiática ficam limitados e tem pouca margem para desafiar esse ambiente dos meios, ocasionando em pouco espaço à expressão de uma cultura imagética mais ajustada à identidade grega contemporânea.

E se, portanto, a cultura da imagem for suplantada pela cultura das telas, a cabeça simbólica do bloco de poder emergente da nova mídia, se colcou como a expressão do poder simbólico atual, passando a configurar seus apelos por uma "cultura das telas". Essa "cultura das telas" assinala um tipo de unificação das possibilidades da "cultura da imagem" em direção a um tipo de cultura de convergência. Em tal cultural, o impresso, o som e as imagens estariam unificadas por meio dos aparelhos eletrônicos, fornecendo aos usuários possibilidades nunca antes pensadas, causando-lhes uma apraente sensação de empoderamento social que, no nosso ver, não é verdadeira em termos emancipatórios e

\footnotetext{
${ }^{8}$ Ver matéria "Berlusconi relishes power of TV". http://news.bbc.co.uk/2/hi/europe/4744196.stm Acessado em 04/02/2011.

${ }^{9}$ Nota do tradutor: TINA (Theres Is No Alternative) no texto original em inglês.
} 
que acomodam estes indivíduos na nova lógica de organização do capitalismo em seu estágio atual.

A base material para a constituição de uma cultura de convergência já tinha sido evidenciada em um número de lares gregos; o incremento de aparelhos de televisão, DVD, e consolas de vídeo jogos, projetores, mas também iPods e iPads (os últimos aparelhos da mídia cognoscenti) já estavam presentes neste contexto.

Tabela 2 - Evolução da complexidade dos aparelhos relacionados com a Televisão Fonte - Establishment Surveys, Nielsen Audience Measurement (2010).

\begin{tabular}{|l|l|l|l|l|}
\hline $\begin{array}{l}\text { Aparelhos } \\
\text { relacionados com } \\
\text { a Televisão }\end{array}$ & $\mathbf{1 9 9 8}$ & $\mathbf{2 0 0 3}$ & $\mathbf{2 0 0 8}$ & $\mathbf{2 0 1 0}$ \\
\hline 2+TV & $51.3 \%$ & $57.2 \%$ & $69.7 \%$ & $69.2 \%$ \\
\hline $3+\mathrm{TV}$ & 9.7 & 14.5 & 25.5 & 24.4 \\
\hline Nova & - & 3.2 & 8.4 & 9.9 \\
\hline DVD/HD (Hard Disk) & - & 16.6 & 68.7 & 71.5 \\
\hline Consola Vídeo Jogo & - & - & 20.8 & 20.8 \\
\hline Home Theater & - & - & 10.9 & 12.8 \\
\hline Projetor & - & - & 2.0 & 2.1 \\
\hline Computador & - & 29.2 & 52.5 & 62.5 \\
\hline Internet & - & 18.3 & 38.7 & 53.6 \\
\hline
\end{tabular}

Contudo, depois do final da década anterior, e como resultado da atmosfera gerada pelo retrocesso financeiro internacional, do declínio do investimento publicitário, do aprofundamento da crise financeira na Grécia, a festa do consumo infinito começou mostrar uma indiscriminada queda. As medidas de austeridade financeiras impostas sobre a Grécia guiaram o caminhou da queda do investimento publicitário, e uma retraída em termos de consumo. Do mesmo modo, claramente, hoje em dia o empréstimo ao consumidor é coisa do passado. Tudo culminou numa situação da riqueza à pobreza, com um final ainda não previsível. De forma consequente, houve um tipo de rearranjo dos conglomerados de mídia devido, em parte, ao cataclismo das mudanças tecnológicas.

O extremamente difícil o clima fiscal da Grécia, a rápida queda no consumo global, o deslocamento completo e desaparecimento no ar de estilos de consumo amplamente aceitos (como o conceito de estilo de vida, empurrando as pessoas para um consumo desenfreado), a depressão psicológica generalizada, a péssima situação 
financeira da mídia de massa e o clima político global: a combinação de todos esses fatores resultou numa queda significativa do investimento em publicidade e, portanto, a perdas significativas de receita publicitária para os meios de comunicação de massa (e para os respectivos conglomerados de mídia).

$\mathrm{Na}$ Grécia, parece que agora estamos aprendendo viver nossas vidas juntamente com os vários sistemas mídiaticos (incluindo, principalmente, os novos meios de comunicação), com pessoas pertencentes aos grupos etários mais jovens como principais motores. De fato, uma série de resultados de pesquisas qualitativas apontam para o aspecto de que há uma brecha significativa entre as pessoas com idade acima de 24 anos de idade, no que diz respeito aos usos dos meios de comunicação. O grupo dos menores de 25 anos já adota e utiliza com muito mais frequência as novas mídias (ou seja, a Internet e suas diversas manifestações, por exemplo, redes sociais). $\mathrm{O}$ grupo com mais de 25 anos são principalmente os antigos usuários de mídia, os telespectadores tradicionais, ouvintes de rádio e usuários muito mais regulares da mídia impressa.

Todos os dados mencionados anteriormente assinalam a criação de um ambiente de mídia radicalmente diferente do que o antigo, existente há cinco ou dez anos atrás. Esse novo ambiente midiático também apresenta uma tendência para as protaformas de comunicação multitarefas, o que é facilitado pelo potencial de desenvolvimento do campo digital. Esta tendência mostra sinais claros de ser um fenômeno crescente, uma vez que parece ser amplamente adotada e usada pelas gerações mais jovens e, naturalmente, por aqueles por vir.

No entanto, a situação financeira das grandes empresas de mídia (os jogadoreschave na mídia de massa na Grécia), está em declínio, pelo menos nos últimos três anos, e ainda continua em uma direção negativa. Isso resultou em um grande número de demissões de pessoal, suspensão de um grande número de publicações, retiradas de empresas da bolsa de valores, como é o caso das Edições Lyberis e do Grupo Imako (entre outros), as duas empresas sendo até recentemente bastante fortes no setor das revistas. Todos os pontos assinalados nos parágrafos acima se apresentam como o 
resultado de uma "bolha de dentro de uma bolha" ${ }^{10}$, ilustrando ao mesmo tempo, o aparecimento de "fenômenos degenerativos" nos meios de comunicação gregos ${ }^{11}$.

A situação foi ainda mais agravada pela diminuição da publicidade do Estado, devido à restrição dos orçamentos de publicidade severamente afetados pelas medidas de austeridade fiscal, decididas pelo governo Grego. Um novo projeto de lei que busca gerar uma reestruturação das relações entre a mídia e o governo está prevista para ser discutido no Parlamento durante os próximos meses ${ }^{12}$. É uma tentativa clara, por parte do governo, de reorganizar as relações de ambos fatores mencionados no novo ambiente da mídia, portanto, a criação de novos equilíbrios, tendo em vista as grandes mudanças tecnológicas presentes e futuras.

Tem-se observado nas últimas décadas após a queda da junta militar do pósguerra, (1974) que aproximadamente cada dez anos ou mais, o sistema de mídia está sendo reformulado, criando assim uma melhor posição para as empresas que estavam atrasadas durante reorganização anterior. No entanto, os avanços tecnológicos durante estas décadas não tem sido tão significativos quando relacionados com as atuais, assim como os padrões de consumo de mídia para as audiências mas restritas se mantiveram quase iguais.

Mas isso não é mais assim. A credibilidade do meio de comunicação mais importante (ou seja a Televisão) está no seu nível mais baixo, as vendas de jornais e revistas estão obedecendo a sempre presente lei da gravidade. Os novos meios de comunicação com a Internet estão na frente, ganhando prestígio e uma nova credibilidade _ainda que discutível _, assim como os padrões de consumo de conteúdo da mídia estão mudando rápida e radicalmente; em ressumo, é um mundo em movimento.

\section{PANORAMA E CONSIDERAÇÕES FINAIS}

\footnotetext{
${ }^{10}$ The 20-year cycle and the new media “, in newspaper "Prin", 19/12/2010, 2010, p. 7 (Em grego ).

${ }^{11}$ Louka,M "Mass Media: Financial collapse, interweaving and infotainment ( uma tradução do termo diaploki em grego): Por Maria Louka, in syspeirosi.wordpress.com/2010/09/16/. Acesso em 26 /3/2011. (Em grego).

${ }^{12} \mathrm{O}$ projeto inclui disposições sobre impostos sobre a publicidade (por exemplo, o chamado aggeliosimo), a publicação de balanços financeiros na mídia impressa, a transição para o digital, as licenças para emissoras de TV, fusões, blogs de internet e da Televisão estatal da ERT . Um novo projeto de lei para a mídia de massa é iminente, na revista Ad Business, segunda-feira de 30/05/2011, No. 738, p.12. Ver também Papachristoudi, Matina "A nova era para a mídia de massa está sendo formado agora", no jornal "O dromos tis aristeras". 07/05/2011, p. 24 (Em grego). sábado 07/05/2011, p. 24.
} 
Transição é a palavra chave para o "ambiente" da mídia na Grécia, e, certamente, não só para a situação desse lugar. Durante os últimos anos temos visto o deslocamento dos conglomerados de mídia mais velhos, e a formação de uma cena da mídia completamente nova, resultando na reestruturação tectônica do "velho" contrato entre o Estado e o grupo de empresários, ou seja, o velho vínculo que era caracterizado como "entrelaçamento" (diaploki em grego).

Tendo em vista as severas medidas fiscais impostas sobre a economia grega pelo coro do BCE, do FMI e da UE, é altamente provável que o fluxo quase contínuo de publicidade vai diminuir por um bom número de anos. A solução do problema da realização da mais-valia para as atividades publicitárias na Internet vai obter um caráter de urgência, uma vez que está relacionado diretamente com a própria viabilidade de tudo o que denominamos de novo bloco de poder. Dentro de tal contexto, a pesquisa e uma melhor compreensão sobre a economia política da Internet $^{13}$ é de uma importância fundamental.

Pode-se notar que as empresas de mídia existentes envolvem-se com tecnologias que não se presta, facilmente ao controle corporativo e, portanto, à exploração rentável. Consequentemente, elas podem tentar envolver esses novos públicos, em termos de ganância financeira, com elementos como conteúdo premium, pay-per-view, TV por assinatura, entre outros, tomando uma distância acentuada de modelos suportados pela publicidade. Esta decisão implica um esforço contínuo de sua parte, uma vez que estes novos públicos gastam o tempo em várias formas de interação mediada, a partir do qual a obtenção de mais-valia é cada vez mais difícil para as empresas.

O ponto crucial nesta fase de transição é a prática cada vez maior de multitasking, por meio do uso de computadores, e as diferentes manifestações da cultura das telas, combinada com um aumento significativo na utilização da Internet, em particular dos grupos etários entre 16 - 24, 25-34 e 35-44 anos de idade, tal como pode ser observado no seguinte quadro:

\footnotetext{
${ }^{13}$ Ver o ensaio "Contribution to the Critique of the Political Economy of the Internet" em Christian Fuchs (2009).
} 
Tabela 3- Acesso e uso da Internet (\% de pessoas que utilizam a Internet pelo menos uma vez durante os últimos três meses)

Fonte - Measurement of indices eEurope/i2010 for Greece, observatory.gr, July 2009

\begin{tabular}{|l|l|l|l|l|}
\hline Grécia & $\mathbf{2 0 0 5}$ & $\mathbf{2 0 0 6}$ & $\mathbf{2 0 0 7}$ & $\mathbf{2 0 0 8}$ \\
\hline $\mathbf{1 6 - 2 4}$ & $42.3 \%$ & $48.4 \%$ & $63.3 \%$ & $76.5 \%$ \\
\hline $\mathbf{2 5 - 3 4}$ & 30.1 & 32.7 & 44.6 & 59.9 \\
\hline $\mathbf{3 5 - 4 4}$ & 19.9 & 27.1 & 32.6 & 43.3 \\
\hline
\end{tabular}

A nova linha divisória está virando cada vez mais aparente; os jovens entre 16 44 anos de idade, e principalmente o grupos dos com menos 25 anos que utilizam, sobretudo, os novos meios de comunicação, enquanto que o uso dos meios de comunicação tradicionais ainda continua a ser a fortaleza do grupo dos com mais de 25 anos, e mais marcadamente do grupo dos com mais de 45 anos. Isso, é claro, ajuda a criar diferentes percepções relacionadas com a mediação da vida cotidiana do consumo, o conteúdo midiático, etc. Embora, temos que apontar para o fato de que a Internet não é apenas outro meio, mas é a pré-condição para a comunicação per se.

Mesmo que essa visão inclui afirmações políticas, a Internet continua sendo um campo de batalha para o controle (através de vários regulamentos impostos pelo Estado, por exemplo, sob o motivo da proteção contra o terrorismo, ou algum outro pretexto "adequado") e a criatividade (através da exploração da sua capacidades realmente importantes por parte dos cidadãos, que foram anteriormente representados como consumidores).

\section{REFERÊNCIAS BIBLIOGRÁFICAS}

FUNCHS, C. Information and Communication Technologies and Society. A Contribution to the Critique of the Political Economy of the Internet, European Journal of Communication. Los Angeles, London, New Delhi and Singapore: SAGE Publications v. 24, n. 1 pp. 69-87. D.O.I [10.1177/0267323108098947].

http://www.sagepub.com/mcquail6/Online\%20readings/9d\%20Fuchs.pdf Acessado em 26/06/2011. 
HERETAKIS, E. Os meios de comunicação, publicidade e consumo na Grécia, 19602000. Atenas: University Press Edições ,Thessaloniki. 2010. PP. 479-590. (Tradução do título da obra publicada em Grego).

YANNOPOULOS, D. Greek media groups come of age. In newspaper Athens News 26 de março, 2011. athensnews.gr/issue/13345/19514. Acessado em 28/3/2011. (Em Grego).

HALLIN, D.C.; MANCINI ,P. Comparing Media Systems -Three Models of Media and Politics. Cambridge: Cambridge University Press. 2004. Pp. 114-115.

OBSERVATORY. Measurement of indices eEurope/i2010 for Greece, July, 2009.

PAPACHRISTOUDI, M. A nova era para a mídia de massa está sendo formado agora". In: $O$ dromos tis aristeras. 07/05/2011, p. 24. (Em grego).

The 20-year cycle and the new media. In: Newspaper Prin, 19/12/2010, 2010, p. 7 (Em grego ).

TILETHEATI, D. Private television or oligopolistic pluralism. Revista Anti. n. 412. 11/08/1989. p. 40. (Em Grego).

Um novo projeto de lei para a mídia de massa é iminente. In: Revista Ad Business. 30/05/ 2011, n. 738, p.12. (Em Grego).

$\underline{\text { Sites Consultados }}$

http://media.mediaservices.gr/home/msindex_en.asp Acessado em 11/11/2012.

Berlusconi relishes power of TV em http://news.bbc.co.uk/2/hi/europe/4744196.stm Acessado em 04/02/2011.

LOUKA, M. Mass Media: Financial collapse, interweaving and infotainment (uma tradução do termo diaploki em grego): Por Maria Louka In: syspeirosi.wordpress.com/ 2010/09/16/ . Acesso em 26 /3/2011 ( Em grego) do em $26 / 3 / 2011$.

Artigo submetido: 30/11/2012.

Artigo aprovado: 06/06/2013 